\title{
ANALISIS PENGARUH PROFESIONALISME PEGAWAI DAN GAYA KEPEMIMPINAN TERHADAP KINERJA PEGAWAI DI KANTOR CABANG BRI TB SIMATUPANG JAKARTA SELATAN
}

\author{
Wasis Gunadi $^{1}$ dan Agus Panti Kustianto ${ }^{2}$
}

\begin{abstract}
ABSTRAK
Penelitian mengenai faktor - faktor yang mempengaruhi kinerja karyawan diantaranya adalah profesionalisme pegawai dan gaya kepemimpinan. Penelitian dengan judul "Analisis Pengaruh profesionalisme Pegawai dan Gaya Kepemimpinan terhadap Kineja Pegawai di Kantor Cabang BRI, TB Simatupang, Jakarta Selatan”. Penelitian tersebut dilaksanakan untuk meneliti korelasi dan pengaruh variabel tersebut terhadap Kinerja Pegawai.

Tempat pelaksanaan penelitian ini adalah di Bank BRI Cabang TB Simatupang, Jakarta Selatan. Seluruh karyawan yang bekerja di BRI Cabang TB Simatupang.Metode Penelitian yang digunakan adalah dengan menggunakan Regresi Linear Berganda, dengan menyebarkan angket atau kuisioner yang diuji validitas dan reliabilitasnya sebelum di sebarkan ke responden, setelah melalui uji persyaratan analisis, yaitu, uji homogenitas, uji normalitas dan uji linearitas, maka dilanjutkan dengan uji hipotesis,

Penelitian ini menyimpulkan bahwa Profesionalisme Pegawai mempunyai pengaruh positif terhadap Kinerja Pegawai, Gaya Kepemimpinan berpengaruh positif terhadap Kinerja Pegawai, Profesionalisme Pegawai dan Gaya Kepemimpinan mempunyai pengaruh terhadap Kinerja Pegawai, dengan koefisien determinasi (adjusted $R^{2}$ ) yang diperoleh sebesar 0,367 atau 36,7 \%, sedangkan 63,3\% adalah faktor lain yang tidak diteliti dalam penelitian ini.

Pada taraf nyata 0,05 Profesionalisme Pegawai dan Gaya Kepemimpinan berpengaruh positif terhadap Kinerja Pegawai. Profesionalisme Pegawai memberikan kontribusi sebesar 0,587 terhadap Kinerja Pegawai, yang berarti bahwa jika Profesionalisme Pegawai meningkat satu unit, maka Kinerja Pegawai juga mengalami peningkatan, sebesar 0,587 unit. Kontribusi Gaya Kepemimpinan terhadap Kinerja Pegawai adalah sebesar 0,192, artinya jika Gaya Kepemimpinan meningkat satu unit, maka Kinerja Pegawai mengalami peningkatan sebesar 0,192 unit.
\end{abstract}

\section{PENDAHULUAN}

Sumber Daya Manusia (SDM) mempunyai peran yang sangat penting, maka penanganan sumber saya manusia berbeda dengan sumber daya yang lainnya, dikarenakan Sumber Daya Manusia(SDM) selalu berkembang dan bertambah baik kualitas dan kuantitasnya, sehingga akan diperoleh kinerja pegawai secara maksimal. Terdapat beberapa faktor yang mempengaruhi kinerja pegawai, antara lain profesionalisme dan gaya kepemimpinan.

Kepemimpinan didefinisikan sebagai kemampuan yang dimiliki seseorang untuk mempengaruhi orang lain agar bekerja mencapai tujuan dan sasaran, Patola dalam Ummah(2011:6).

Kemampuan mempengaruhi yang dimiliki seorang pimpinan akan menentukan cara yang digunakan pegawai bawahannya dalam mencapai hasil kerja yang maksimal. Hal ini didasarkan pada argument yang menyatakan 
bahwa seorang pemimpin memiliki otoritas dalam merencanakan, mengarahkan, mengkoordinasikan, dan mengawasi perilaku pegawai sesuai dengan fungsi dari manajemen. Seorang pemimpin dianggap baik jika mau menerima adanya perubahan, mau menerima kritik dan saran dari bawahan secara terbuka, dan sering memperhatikan kesejateraan mereka.

Kinerja pegawai merupakan salah satu faktor utama yang dapat mempengaruhi kemajuan perusahaan. Semakin tinggi atau semakin baik kinerja pegawai maka tujuan perusahaan akan semakin mudah dicapai, begitu pula sebaliknya, apabila kinerja pegawai rendah atau tidak baik, maka tujuan itu akan sulit dicapai. Oleh karena itu upayaupaya untuk meningkatkan kinerja pegawai merupakan suatu tantangan manajemen perusahaan, karena keberhasilan untuk mencapai tujuan dan kelangsungan hidup perusahaan tergantung pada kualitas kinerja sumber daya manusia yang ada didalamnya.

Kinerja Bank Rakyat Indonesia secara umum dan Bank Rakyat Indonesia Kantor Cabang TB Simatupang , Jakarta Selatan secara khusus saat ini tidak terlepas dari profesionalisme pegawai dan gaya kepemimpinan. Data kinerja pegawai Bank Rakyak Indonesia Cabang TB Simatupang tahun 2013 dibandingkan tahun 2014 mengalami penurunan. Untuk dapat meningkatkan kinerja pegawai PT Bank Rakyat Indonesia Cabang TB Simatupang atau setidaknya mempertahankan kinerja yang sudah diraih saat ini agar tidak terjadi penurunan secara drastis, kiranya perlu dikaji ulang setiap faktor yang berperan di dalamnya, yaitu profesionalisme dan gaya kepemimpinan untuk dapat mendukung peningkatan kinerja pegawai.

Salah satu permasalahan yang dihadapi Bank Rakyat Indonesia Kantor Cabang TB Simatupang, Jakarta Selatan adalah keterlambatan pegawai. Keterlambatan pegawai menunjukkan peningkatan dari tahun 2013 ke tahun 2014 (ditunjukkan pada Tabel di bawah ini).

Tabel

. Keterlambatan pegawai PT BRI Cabang TB.Simatupang.

2013

\begin{tabular}{|c|c|}
\hline TRIWULAN & $\begin{array}{c}\text { Jumlah } \\
\text { keterlambaan } \\
\text { (hari) }\end{array}$ \\
\hline TRIWULAN 1 & 15 \\
\hline TRIWULAN 1I & 22 \\
\hline TRIWULAN III & 30 \\
\hline TRIWULAN 1V & 20 \\
\hline
\end{tabular}

Sumber : Kepegawaian BRI TB Simatupang

Tabel

Keterlambatan pegawai PT BRI Cabang TB.Simatupang. Tahun 2014

\begin{tabular}{|c|c|}
\hline Triwulan & $\begin{array}{c}\text { Jumlah } \\
\text { keterlambatan } \\
\text { (hari) }\end{array}$ \\
\hline Triwulan I & 30 \\
\hline Triwulan II & 25 \\
\hline Triwulan III & 38 \\
\hline Triwulan IV & 32 \\
\hline
\end{tabular}

Sumber : Kepegawaian BRI TB Simatupang 
Berdasarkan fenomena tersebut di atas, maka dirasakan perlu untuk meneliti "Pengaruh Profesionalisme Pegawai dan Gaya Kepemimpinan terhadap Kineja Pegawai di Kantor Cabang PT BRI, TB Simatupang, Jakarta Selatan".

\section{TUJUAN DAN MANFAAT PENELITIAN}

Tujuan dari penelitian ini adalah untuk mengetahui pengaruh profesionalisme pegawai dan gaya kepemimpinan terhadap kinerja pegawai di PT BRI Cabang TB.Simatupang Jakarta .

Penelitian ini diharapkan dapat bermanfaat antara lain bagi :

1) Peneliti: menambah ruang lingkup bidang penelitian, khususnya penelitian mengenai pengembangan kinerja SDM.

2) Bagi Perusahaan

Penelitian ini diharapkan bisa memberikan kontribusi untuk menyusun kebijakan yang lebih baik, khususnya kebijakan pengembangan kepemimpinan dan profesionalisme pegawai dalam rangka peningkatan kinerja pegawai Bank Rakyat Indonesia Kantor Cabang TB Simatupang, Jakarta Selatan.

\section{KERANGKA BERPIKIR}

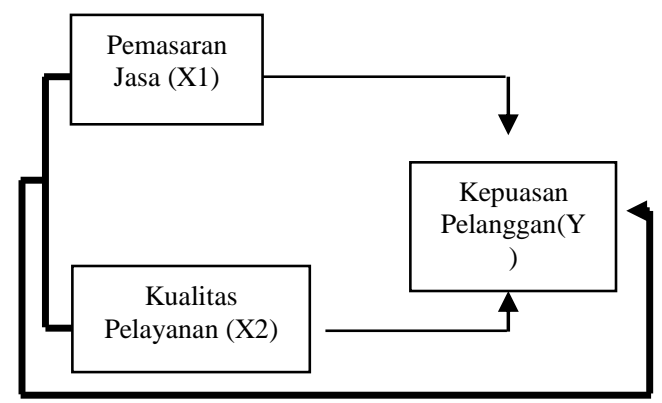

\section{HIPOTESA}

a. $\mathrm{H}_{\mathrm{o}}=$ Tidak terdapat pengaruh secara simultan Profesionalisme Pegawai ( $\mathbf{X}_{\mathbf{1}}$ ) dan Gaya Kepemimpinan ( $\mathbf{X}_{\mathbf{2}}$ ) terhadap Kinerja Pegawai (Y) BRI Cabang Simatupang.

$\mathrm{H}_{\mathrm{a}}=$ Terdapat pengaruh secara parsial simultan Profesionalisme Pegawai ( $\mathbf{X}_{\mathbf{1}}$ ) dan Gaya Kepemimpinan ( $\mathbf{X}_{\mathbf{2}}$ ) terhadap Kinerja Pegawai (Y) BRI Cabang Simatupang.

b. $\mathrm{H}_{01}=$ Tidak terdapat pengaruh secara parsial Profesionalisme Pegawai ( $\mathbf{X}_{1}$ )

terhadap Kinerja Pegawai (Y) BRI Cabang Simatupang

$\mathrm{H}_{\mathrm{a} 1}=$ Terdapat pengaruh secara parsial Profesionalisme Pegawai $\left(\mathbf{X}_{\mathbf{1}}\right)$ terhadap Kinerja Pegawai (Y) BRI Cabang Simatupang.

c. $\mathrm{H}_{02}=$ Tidak terdapat pengaruh secara parsial Gaya Kepemimpinan ( $\left.\mathbf{X}_{2}\right)$ terhadap Kinerja Pegawai (Y) BRI Cabang Simatupang.

$\mathrm{H}_{\mathrm{a} 2}=$ Terdapat pengaruh secara parsial Gaya Kepemimpinan $\left(\mathbf{X}_{\mathbf{2}}\right)$ terhadap 
Kinerja Pegawai (Y) BRI Cabang Simatupang.

\section{METODOLOGI PENELITIAN}

\section{Tempat dan Waktu Penelitian}

Penelitian ini dilakukan di Bank BRI Cabang TB Simatupang, Jakarta Selatan. Seluruh karyawan yang bekerja di BRI Cabang TB Simatupang, selama enam bulan, sejak bulan Maret 2015 sampai dengan bulan Agustus 2015.

\section{Populasi dan Sampel}

Populasi penelitian adalah pegawai BRI Kanca TB Simatupang sebanyak 120 orang yang terdiri dari Pegawai Tetap BRI sebanyak 40 orang, Pegawai Kontrak BRI sebanyak 60 orang, dan Pegawai Outsourching sebanyak 20 orang. Dari 120 orang anggota populasi, diambil sampel yang beranggotakan 100 pegawai, yang terdiri dari 40 orang pegawai tetap BRI dan 60 orang pegawai kontrak BRI.

Data diperoleh dari pengumpulan data primer dan sekunder dari beberapa sumber/lembaga. Instrumen utama dalam pengumpulan da primer berupa kuisioner yang dibagikan pada responsedn (anggota sample) yang terdiri dari kuisioner untuk variabel-variabel Profesionalisme Pegawai, Gaya Kepemimpinan dan Kinerja Pegawai.

\section{METODE ANALISIS}

Penelitian ini menggunakan metode analisis deskriptif dan inferensia. Dalam analisis deskriptif disajikan bahan analisis berupa ukuran pemusatan, letak dan penyebaran seperti mean, modus, media dan simpangan baku, juga digunakan ukuran skewness dan kurtosis untuk menggambarkan distribusi data apakah normal atau tidak, dilengkapi dengan beberapa pengujian untuk mengetahui normalitas data dengan uji Kolmogorov-Smirnov dan Shapiro-Wilk. Dalam pembahasan ini hanya akan dilakukan analisis deskriptif dengan memberikan gambaran data tentang jumlah data, minimum, maksimum, mean, dan standar deviasi. Sedangkan dalam analisis inferensia dignunakan analisis regeresi berganda bertujuan untuk meramalkan nilai-nilai Variabel tak bebas atau Variabel terikat(dependen )Y berdasarkan dengan hasil pengukuran pada Variabel bebas(independen) $\mathrm{X}_{1}, \mathrm{X}_{2}, \quad$ maka untuk menganalisis hubungan Profesionalisme Karyawan, Gaya Kepemimpinan, dengan Kinerja akan digunakan analisis tersebut dengan model persamaan sebagai berikut ini :

$$
\mathbf{Y}=\mathbf{a}+\mathbf{b}_{1} \mathbf{X}_{1}+\mathbf{b}_{2} \mathbf{X}_{2}+\mathbf{e}
$$

dimana: Y: Kinerja, a: konstanta, b1-b2 : koefisien regresi, $\mathbf{X}_{\mathbf{1}}$ : Profesionalisme Pegawai, dan $\mathbf{X}_{2}$ : Gaya Kepemimpinan Perhitungan model ini akan dihitung dengan mempergunakan perangkat lunak analisis statistik SPSS Version 20.0 pada komputer. 


\section{JURNAL M-PROGRESS}

Tabel

Kisi-Kisi Instrumen Penelitian berkenaan dengan uji validitas

\begin{tabular}{|c|c|c|}
\hline Variabel & $\begin{array}{l}\text { Definisi } \\
\text { Indikator }\end{array}$ & Pernyataan \\
\hline $\begin{array}{l}\text { Profesionalis } \\
\text { me } \\
\text { Pegawai }\end{array}$ & $\begin{array}{l}\text { Pengetahuan } \\
\text { dan skill yang } \\
\text { cukup }\end{array}$ & $\begin{array}{l}\text { 1. Mampu melakukan pekerjaan pada Tempat yang } \\
\text { berbeda. } \\
\text { 2. Mampu bekerja pada suasana kerja yang } \\
\text { berbeda. } \\
\text { 3. Mampu bekerjasama dengan rekan yang baru } \\
\text { di tempat yang berbeda. } \\
\text { 1. Punya pengetahuan yang cukup untuk } \\
\text { melakukan pekerjaan. } \\
\text { 2. Punya skill yang cukup untuk melakukan } \\
\text { pekerjaan. } \\
\text { 3. Pengetahuan dan skill masih mampu untuk } \\
\text { ditingkatkan. } \\
\text { 1. Mampu menjalankan tugas yang diberikan } \\
\text { atasan. } \\
\text { 2. Mampu berfungsi pada jabatan yang diberikan }\end{array}$ \\
\hline $\begin{array}{l}\text { Gaya } \\
\text { Kepemimpinan }\end{array}$ & $\begin{array}{l}\text { Kepemimpinan } \\
\text { Suportive. } \\
\\
\text { Kepemimpinan } \\
\text { Participating }\end{array}$ & $\begin{array}{l}\text { 1. Pimpinan mengambil keputusan dengan tepat } \\
\text { dan hati-hati. } \\
\text { 2.Pimpinan punya keahlian dan pendidikan yang } \\
\text { sesuai. } \\
\text { 3. Dapat bekerja dengan efektif } \\
\text { 1.Pimpinan selalu memberikan contoh yang } \\
\text { baik. } \\
\text { 2.Pimpinan memberikan arahan bagi anak buah. } \\
\text { 3.Pimpinan bersikap adil terhadap bawahan. } \\
\text { 1.Pimpinan memberikan motivasi dan saran bagi } \\
\text { anak buah. } \\
\text { 2.Pimpinan memberikan penghargaan atas prestasi } \\
\text { karyawan }\end{array}$ \\
\hline Kinerja & Perencanaan & $\begin{array}{l}\text { 1.Karyawan mampu dalam membuat rencana } \\
\text { pekerjaan sehingga efisien } \\
\text { 2.Karyawan mampu dalam membuat rencana } \\
\text { pekerjaan sehingga efektif } \\
\text { 1. Peningkatan ketepatan kerja karyawan } \\
\text { menjadi lebih baik dalam menyelesaikan } \\
\text { pekerjaan sesuai dengan keinginan lembaga. } \\
\text { 2. Kinerja tim sangat mendukung dalam } \\
\text { peningkatkan produktivitas lembaga. } \\
\text { 3. Karyawan melaksanakan Pekerjaan } \\
\text { sesuai dengan perencanaan. }\end{array}$ \\
\hline
\end{tabular}




\section{JURNAL M-PROGRESS}

\begin{tabular}{|l|l|l|}
\hline Evaluasi & $\begin{array}{l}\text { 1. Peningkatan ketepatan kerja karyawan } \\
\text { menjadi lebih baik dalam menyelesaikan } \\
\text { pekerjaan sesuai dengan keinginan lembaga. } \\
\text { 2. Kinerja tim sangat mendukung dalam } \\
\text { peningkatan produktivitas lembaga } \\
\text { 3. Karyawan melaksanakan Pekerjaan sesuai } \\
\text { dengan perencanaan. }\end{array}$ \\
\hline
\end{tabular}

Tabel

Hasil uji validitas:

\begin{tabular}{|l|l|l|l|l|l|}
\hline Variabel & Butir & r tabel & r hitung & Siginifikansi & Keterangan \\
\hline \multirow{5}{*}{ X $_{1}$} & Butir 1 & 0,444 & 0,950 & 0,000 & Valid \\
\cline { 2 - 6 } & Butir 2 & 0,444 & 0,911 & 0,000 & Valid \\
\cline { 2 - 6 } & Butir 3 & 0,444 & 0,456 & 0,043 & Valid \\
\cline { 2 - 6 } & Butir 4 & 0,444 & 0,951 & 0,000 & Valid \\
\cline { 2 - 6 } & Butir 5 & 0,444 & 0,007 & 0,977 & Tidak Valid \\
\cline { 2 - 6 } & Butir 6 & 0,444 & 0,165 & 0,488 & Tidak Valid \\
\cline { 2 - 6 } & Butir 7 & 0,444 & 0,871 & 0,000 & Valid \\
\cline { 2 - 6 } & Butir 8 & 0,444 & 0,889 & 0,000 & Valid \\
\hline \multirow{5}{*}{ X } & Butir 1 & 0,444 & 0,794 & 0,000 & Valid \\
\cline { 2 - 6 } & Butir 2 & 0,444 & 0,929 & 0,000 & Valid \\
\cline { 2 - 6 } & Butir 3 & 0,444 & 0,904 & 0,000 & Valid \\
\cline { 2 - 6 } & Butir 4 & 0,444 & 0,864 & 0,000 & Valid \\
\cline { 2 - 6 } & Butir 5 & 0,444 & 0,801 & 0,000 & Valid \\
\cline { 2 - 6 } & Butir 6 & 0,444 & 0,918 & 0,000 & Valid \\
\cline { 2 - 6 } & Butir 7 & 0,444 & 0,216 & 0,359 & Tidak Valid \\
\cline { 2 - 6 } & Butir 8 & 0,444 & 0,325 & 0,163 & Tidak Valid \\
\hline Y & Butir 1 & 0,444 &, 016 &, 946 & Tidak Valid \\
\cline { 2 - 6 } & Butir 2 & 0,444 & 0,899 &, 000 & Valid \\
\cline { 2 - 6 } & Butir 3 & 0,444 & 0,492 &, 028 & Valid \\
\hline & Butir 4 & 0,444 & 0,619 &, 004 & Valid \\
\hline & Butir 5 & 0,444 &, 028 &, 906 & Tidak Valid \\
\hline & Butir 6 & 0,444 & 0,618 &, 004 & Valid \\
\cline { 2 - 5 } & Butir 7 & 0,444 & 0,844 &, 000 & Valid \\
\cline { 2 - 5 } & Butir 8 & 0,444 & 0,796 &, 000 & Valid \\
\hline
\end{tabular}

Sumber: Data primer yang diolah, 2015 
Kinerja (Y)

Dari hasil pengolahan data , maka butirbutir pernyataan variabel Profesionalisme $\left(\mathrm{X}_{1}\right)$ dari 8 pertanyaan nomor 5 dan 6 tidak valid, Gaya Kepemimpinan $\left(\mathrm{X}_{2}\right)$ pertanyaan nomor 7 dan 8 tidak valid dan Kinerja pertanyaan nomor 1 dan 5 tidak valid dilihat dari nilai $r$ hitung $>r_{\text {tabel. }}$

Adapun hasil uji realibilitas disajikan pada tabel berikut:

Tabel

Uji Reliabilitas Pada Setiap Variabel

Profesionalisme $\left(\mathrm{X}_{1}\right)$

Reliability Statistics

\begin{tabular}{|r|r|r|}
\hline $\begin{array}{c}\text { Cronbach's } \\
\text { Alpha }\end{array}$ & $\begin{array}{c}\text { Cronbach's } \\
\text { Alpha Based } \\
\text { on } \\
\text { Standardized } \\
\text { Items }\end{array}$ & N of Items \\
\hline, 727 &, 747 & 8 \\
\hline
\end{tabular}

Gaya Kepemimpinan $\left(\mathrm{X}_{2}\right)$

\section{Reliability Statistics}

\begin{tabular}{|r|r|r|}
\hline $\begin{array}{c}\text { Cronbach's } \\
\text { Alpha }\end{array}$ & $\begin{array}{c}\text { Cronbach's } \\
\text { Alpha Based } \\
\text { on } \\
\text { Standardized } \\
\text { Items }\end{array}$ & N of Items \\
\hline, 775 &, 903 & 8 \\
\hline
\end{tabular}

\section{Reliability Statistics}

\begin{tabular}{|r|c|r|}
\hline $\begin{array}{l}\text { Cronbach's } \\
\text { Alpha }\end{array}$ & $\begin{array}{c}\text { Cronbach's } \\
\text { Alpha Based }\end{array}$ & N of Items \\
& on & \\
& $\begin{array}{c}\text { Standardized } \\
\text { Items }\end{array}$ & \\
&, 767 & \\
\hline, 722 & \\
\hline
\end{tabular}

Dari hasil pengolahan data, maka butir-butir pernyataan variabel Profesionalisme $\left(\mathrm{X}_{1}\right)$, Gaya Kepemimpinan $\left(\mathrm{X}_{2}\right)$ dan $\operatorname{Kinerja}(\mathrm{Y})$ semuanya reliabel dilihat dari nilai Nilai Cronbach Alpha > 0,7.

\section{HASIL PENELITIAN}

\section{Deskripsi Obyek Penelitian.}

Bank Rakyat Indonesia (BRI) adalah salah satu bank milik pemerintah yang terbesar di Indonesia. Pada awalnya Bank Rakyat Indonesia (BRI) didirikan di Purwokerto, Jawa Tengah oleh Raden Bei Aria Wirjaatmadja dengan nama De Poerwokertosche Hulp en Spaarbank der Inlandsche Hoofden atau "Bank Bantuan dan Simpanan Milik Kaum Priyayi Purwokerto", suatu lembaga keuangan yang melayani orang-orang berkebangsaan Indonesia (pribumi). Lembaga tersebut berdiri tanggal 16 Desember 1895, yang kemudian dijadikan sebagai hari kelahiran BRI.

1. Pada periode setelah kemerdekaan RI, berdasarkan Peraturan Pemerintah No. 1 tahun 1946 Pasal 1 disebutkan bahwa BRI 
adalah sebagai Bank Pemerintah pertama di Republik Indonesia. Dalam masa perang mempertahankan kemerdekaan pada tahun 1948, kegiatan BRI sempat terhenti untuk sementara waktu dan baru mulai aktif kembali setelah perjanjian Renville pada tahun 1949 dengan berubah nama menjadi Bank Rakyat Indonesia Serikat.

2. Pada waktu itu melalui PERPU No.41tahun 1960 dibentuklah Bank Koperasi Tani dan Nelayan (BKTN) yang merupakan peleburan dari BRI, Bank Tani Nelayan dan Nederlandsche Maatschappij (NHM). Kemudian berdasarkan Penetapan Presiden (Penpres) No.9 tahun 1965, BKTN diintegrasikan ke dalam Bank Indonesia dengan nama Bank Indonesia Urusan Koperasi Tani dan Nelayan.

3. Setelah berjalan selama satu bulan, keluar Penpres No. 17 tahun 1965 tentang pembentukan bank tunggal dengan nama Bank Negara Indonesia. Dalam ketentuan baru itu, Bank Indonesia Urusan Koperasi, Tani dan Nelayan (eks BKTN) diintegrasikan dengan nama Bank Negara Indonesia unit II bidang Rural, sedangkan NHM menjadi Bank Negara Indonesia unit II bidang Ekspor Impor (Exim).

4. Berdasarkan Undang-Undang No. 14 tahun 1967 tentang Undang-undang Pokok Perbankan dan Undang-undang No. 13 tahun 1968 tentang Undang-undang Bank Sentral, yang intinya mengembalikan fungsi Bank Indonesia sebagai Bank Sentral dan Bank Negara Indonesia Unit II
Bidang Rular dan Ekspor Impor dipisahkan masing-masing menjadi dua Bank yaitu Bank Rakyat Indonesia dan Bank Ekspor Impor Indonesia. Selanjutnya berdasarkan Undang-undang No. 21 tahun 1968 menetapkan kembali tugas-tugas pokok BRI sebagai bank umum.

5. Sejak 1 Agustus 1992 berdasarkan UndangUndang Perbankan No. 7 tahun 1992 dan Peraturan Pemerintah RI No. 21 tahun 1992 status BRI berubah menjadi perseroan terbatas. Kepemilikan BRI saat itu masih $100 \%$ di tangan Pemerintah Republik Indonesia. Pada tahun 2003, Pemerintah Indonesia memutuskan untuk menjual 30\% saham bank ini, sehingga menjadi perusahaan publik dengan nama resmi PT. Bank Rakyat Indonesia (Persero) Tbk., yang masih digunakan sampai dengan saat ini.

\section{Hasil Analisis Deskriptif}

Umur responden yang terbanyak adalah umur kurang atau sama dengan 30 tahun yaitu sebanyak 50 orang atau $50 \%$, diikuti dengan usia responden 31 - 40 tahun sebanyak 20 orang atau $20 \%$, usia responden diatas 30 sebanyak 30 orang atau $30 \%$. Hal ini menunjukkan bahwa pegawai pada BRI Cabang Simatupang. sebagian besar masih berusia muda dan pada umur yang sangat produktif, dengan semangat kerja yang dimiliki masih relatif tinggi. 
Responden terbanyak adalah laki-laki yaitu sebanyak 55 orang $\left(\begin{array}{ll}55 & \%\end{array}\right)$ dibanding perempuan yang hanya 45 orang (45\%).

Jumlah responden yang paling sedikit adalah dari kelompok responden yang berpendidikan S2 yaitu sebanyak 3 orang atau $3 \%$ dari jumlah responden, berpendidikan S1 yaitu sebanyak 23 orang atau $23 \%$ dari jumlah responden, kelompok responden yang berpendidikan D3 yaitu sebanyak 60 orang atau $60 \%$ dari jumlah responden, kemudian kelompok responden yang berpendidikan SLTA yaitu sebanyak 14 orang atau $14 \%$ dari jumlah responden. Hal ini menunjukkan bahwa pegawai BRI Cabang Simatupang sebagian besar memiliki pendidikan atas atau akademis ke atas.

\section{Hasil Analisis Inferensia}

a. Hasil uji homogenitas adalah bahwa variabel-variabel yang diteliti adalah homogen (bervariance sama). Variabel-variabel yang diteliti juga berasal dari populasi yang berdistribusi normal. Selanjutnya hasil uji linieritas antar variabel menunjukkan bahwa hubungan fungsi antara variabel independen dan dependen adalah linier, yang ditunjukkan oleh nilai signifikansi $=0,307$ yang lebih besar dari 0,05 , yang artinya terdapat hubungan linear secara signifikan antara variable Profesionalisme Pegawai (X1) dengan variable Kinerja (Y).

Adapun hasil analisis dan pengujian hipotesis regresi antar variabel adalah sebagai berikut:
Tabel

Hasil Uji Regresi

Coefficients $^{\mathrm{a}}$

\begin{tabular}{|c|c|c|c|c|c|}
\hline \multirow[t]{2}{*}{ Model } & \multicolumn{2}{|c|}{$\begin{array}{c}\text { Unstandar } \\
\text { dized } \\
\text { Coefficient } \\
\text { s }\end{array}$} & $\begin{array}{l}\text { Stan } \\
\text { dardi } \\
\text { zed } \\
\text { Coef }\end{array}$ & $\mathrm{t}$ & $\begin{array}{l}\mathrm{Si} \\
\text { g. }\end{array}$ \\
\hline & B & $\begin{array}{c}\text { Std. } \\
\text { Erro } \\
r\end{array}$ & Beta & & \\
\hline (Constant) & $\begin{array}{r}5,64 \\
3\end{array}$ & $\begin{array}{r}2,24 \\
9\end{array}$ & & $\begin{array}{r}2,5 \\
09\end{array}$ & $\begin{array}{r}, 01 \\
4\end{array}$ \\
\hline $\begin{array}{ll} & \text { X1_Profe } \\
& \text { sionalism } \\
1 & \text { e_Pegawa } \\
& \mathrm{i}\end{array}$ & ,587 & ,093 &, 532 & $\begin{array}{r}6,3 \\
09\end{array}$ & $\begin{array}{r}, 00 \\
0\end{array}$ \\
\hline $\begin{array}{l}\text { X2_Gaya } \\
\text { _Kepemi } \\
\text { mpinan }\end{array}$ & ,192 & ,088 &, 185 & $\begin{array}{r}2,1 \\
99\end{array}$ & $\begin{array}{r}, 03 \\
0\end{array}$ \\
\hline
\end{tabular}

a. Dependent Variable: Y_Kinerja_Pegawai

Sehingga persamaan regresinmya adalah:

$\mathrm{Y}=5,643+0.587 \mathrm{X} 1+0.192 \mathrm{X} 2$,

Keterangan:

$\mathrm{Y}=$ Kinerja pegawai

$\mathrm{X} 1$ = Profesionalisme Pegawai

$\mathrm{X} 2$ = Gaya Kepemimpinan

\section{ANOVA ${ }^{\mathrm{a}}$}

\begin{tabular}{|l|r|r|r|r|r|}
\hline Model & $\begin{array}{c}\text { Sum } \\
\text { of } \\
\text { Squar } \\
\text { es }\end{array}$ & df & $\begin{array}{c}\text { Mea } \\
\mathrm{n} \\
\text { Squa } \\
\text { re }\end{array}$ & F & Sig \\
$\cdot$
\end{tabular}

a. Dependent Variable:

Y_Kinerja_Pegawai

b. Predictors: (Constant),

X2_Gaya_Kepemimpinan,

X1_Profesionalisme_Pegawai

Sumber: Lampiran output SPSS 
Dari persamaan tersebut dapat dijelaskan bahwa:

a. Pengujian pengaruh variabel bebas secara bersama-sama terhadap variabel terikatnya dilakukan dengan menggunakan uji $F$. Hasil perhitungan statistik menunjukkan nilai $\mathrm{F}$ hitung $=29,759$. Dengan menggunakan batas nilai $\mathrm{F}$ tabel $=3,15$, maka $\mathrm{F}$ hitung $>\mathrm{F}$ tabel dengan signifikansi 0,05, maka diperoleh nilai signifikansi tersebut lebih kecil dari 0,000. yang berarti bahwa hipotesis dalam penelitian ini menolak Ho dan menerima Ha. Dengan demikian dapat berarti bahwa hipotesis Ha "Profesionalisme Pegawai dan Gaya Kepemimpinan mempunyai pengaruh terhadap Kinerja Pegawai “ diterima. Artinya, pada taraf nyata 0,05 variabel Profesionalisme Pegawai dan Gaya Kepemimpinan secara simultasn berpengaruh terhadap variabel Kinerja Pegawai.

b. Secara parsial, Profesionalisme Pegawai memberikan kontrobusi sebesar 0,587 terhadap Kinerja Pegawai, yang berarti bahwa jika Profesionalisme Pegawai meningkat satu unit, maka Kinerja Pegawai juga mengalami peningkatan, sebesar 0,587 unit.

c. Secara parsial, kontribusi Gaya Kepemimpinan terhadap Kinerja Pegawai adalah sebesar 0,192, artinya jika Gaya Kepemimpinan meningkat satu unit, maka Kinerja Pegawai mengalami peningkatan sebesar 0,192 unit.

d. Koefisien relasi dan determinasi ditunjukkan oleh hasil berikut::

Tabel

Nilai Koefisien Korelasi dan Determinasi

Model Summary

\begin{tabular}{|l|l|c|c|c|}
\hline $\begin{array}{l}\text { M } \\
\text { od } \\
\text { el }\end{array}$ & $\mathrm{R}$ & $\begin{array}{c}\mathrm{R} \\
\text { Squ } \\
\text { are }\end{array}$ & $\begin{array}{c}\text { Adjust } \\
\text { ed R } \\
\text { Square }\end{array}$ & $\begin{array}{c}\text { Std. } \\
\text { Error } \\
\text { of the } \\
\text { Estima } \\
\text { te }\end{array}$ \\
\hline 1 & $\begin{array}{r}, 617 \\
\mathrm{a}\end{array}$ &, 380 &, 367 & $\begin{array}{r}1,9239 \\
4\end{array}$ \\
\hline
\end{tabular}

a. Predictors: (Constant),

X2_Gaya_Kepemimpinan,

X1_Profesionalisme_Pegawai

Hasil perhitungan regresi dapat diketahui bahwa koefisien determinasi (adjusted $R^{2}$ ) yang diperoleh sebesar 0,367. Hal ini berarti $36,7 \%$ variasi variabel kinerja pegawai dapat dijelaskan oleh variabel Profesionalisme Pegawai dan Gaya Kepemimpinan, sedangkan sisanya sebesar $63.3 \%$ diterangkan oleh variabel lain yang tidak diamati dalam penelitian ini.

\section{KESIMPULAN}

1. Pada taraf nyata Profesionalisme Pegawai dan Gaya Kepemimpinan berpengaruh positif terhadap Kinerja Pegawai.

2. Profesionalisme Pegawai memberikan kontrobusi sebesar 0,587 terhadap Kinerja Pegawai, yang berarti bahwa jika Profesionalisme Pegawai meningkat satu unit, maka Kinerja Pegawai juga 
mengalami peningkatan, sebesar 0,587 unit.

3. Kontribusi Gaya Kepemimpinan terhadap Kinerja Pegawai adalah sebesar 0,192, artinya jika Gaya Kepemimpinan meningkat satu unit, maka Kinerja Pegawai mengalami peningkatan sebesar 0,192 unit.

4. Koefisien determinasi (adjusted $R^{2}$ ) dari hubungan fungsi antara variabel-variabel bebas dengan variabel terikatnya adalah sebesar sebesar 0,367, artinya 36,7\% variasi variabel Kinerja Pegawai dapat dijelaskan oleh variabel Profesionalisme Pegawai dan Gaya Kepemimpinan, sedangkan sisanya sebesar $63.3 \%$ diterangkan oleh variabel lain yang tidak diamati dalam penelitian ini.

\section{DAFTAR PUSTAKA}

Achmad S Ruky. 2003. Sumber Daya Manusia Berkualitas Mengubah Visi menjadi Realitas. Edisi Pertama. Jakarta: PT Gramedia Pustaka Utama.

Ancok, D. 2002. Teknik Penyusunan Skala Pengukur. Pusat Studi Kependudukan dan Kebijakan Universitas Gadjah Mada.Yogyakarta.

Anwar Prabu Mangkunegara. 2005. Sumber Daya Manusia perusahaan. Remaja Rosdakarya: Bandung
Desianti, Mathis , Robert L 2005, "Manajemen Sumber Daya Manusia," Buku 1, Salemba Empat Jakarta.

Filippo, Edwin B.2000. Manajemen Personalia.Penerbit Erlangga. Jakarta

Gomes, Faustino Cardoso, 2003, Manajemen Sumber Daya Manusia, Penerbit Andi, Yogyakarta.

Hani Handoko, 2000, Manajemen Personalia dan Sumber Daya Manusia,Yogyakarta: BPFE

Herman Sofyandi, 2008, Manajemen Sumber Daya Manusia, Edisi Pertama, Penerbit Graha Ilmu, Yogyakarta

Herujito, Yayat M. 2006. Dasar-Dasar Manajemen.PT Grasindo. Jakarta

Kartasasmita, Ginandjar. 1997. Administrasi Pembangunan. Jakarta: LP3ES.

Kartono Kartini. 2008. Pemimpin dan Kepemimpinan. Jakarta: Raja Grafindo

Maharani Puspa and Wismantoro, Yohan (2013) Pengaruh Kepemimpinan, Motivasi, Pelatihan, Lingkungan Kerja Terhadap Kinerja Karyawan Bank BRI Cabang Ahmad Yani Semarang. Skripsi Fakultas Ekonomi Bisnis.

Malayu S.P. Hasibuan, 1998, Manajemen Sumber Daya Manusia, Yogyakarta: Bumi Aksara

Mangkunegara, A.A Anwar Prabu., 2006 Perencanaan dan Pengembangan Sumberdaya Manusia.PT. Refika Aditama, Bandung.

Miftah Thoha (2010), Kepemimpinan dan Manajemen, Devisi Buku Perguruan Tinggi, PT. Raja Grafindo Persada, Kakarta. 


\section{JURNAL M-PROGRESS}

Panggabean, S., Mutiara. 2004. Manajemen Sumber Daya Manusia. Bogor: Ghalia Indonesia

Persada.

Robbins. 2006. Manajemen Sumber Daya Manusia.Penerbit Salemba Empat. Jakarta

Samsudin, Sadili. 2006, Manajemen Sumber Daya Manusia, cetakan ke -1

Siagian, Sondang P. 2008. Manajemen Sumber Daya Manusia. PT Bumi Aksara: Jakarta

Simamora, Henry. 2006. Manajemen Sumber Daya Manusia ,Edisi 2, STIE YKPN.Yogyakarta

Sugiyono. 2002. Metode Penelitian Administrasi. Penerbit Alfabeta, Bandung
Susilo Supardo, 2006, Kepemimpinan, DasarDasar dan Pengembangannya. CV. Andi offset. Yogyakarta.

Tjokrowinoto M. 1996. Pembangunan : Dilema danTantangan. Yogyakarta : Pustaka Pelajar Offset.

Umar, Husein. 2009. Metode Penelitian Untuk Skripsi Dan Tesis Bisnis. Penerbit Rajawali Pers, Jakarta

Ummah Laily, 2011, Pemaknaan Kompensasi Pada Karyawan Kontrak Bagian SalesUniversitas Pendidikan Indonesia repository.upi. 